\title{
Ion Channel Activities in Neural Stem Cells of the Neuroepithelium
}

\author{
Masayuki Yamashita \\ Department of Physiology 1, Nara Medical University, Shijo-cho 840, Kashihara 634-8521, Japan \\ Correspondence should be addressed to Masayuki Yamashita, yama@naramed-u.ac.jp
}

Received 5 March 2012; Revised 2 May 2012; Accepted 9 May 2012

Academic Editor: Michael Levin

Copyright ( $) 2012$ Masayuki Yamashita. This is an open access article distributed under the Creative Commons Attribution License, which permits unrestricted use, distribution, and reproduction in any medium, provided the original work is properly cited.

\begin{abstract}
During the embryonic development of the central nervous system, neuroepithelial cells act as neural stem cells. They undergo interkinetic nuclear movements along their apico-basal axis during the cell cycle. The neuroepithelial cell shows robust increases in the nucleoplasmic $\left[\mathrm{Ca}^{2+}\right]$ in response to $\mathrm{G}$ protein-coupled receptor activation in S-phase, during which the nucleus is located in the basal region of the neuroepithelial cell. This response is caused by $\mathrm{Ca}^{2+}$ release from intracellular $\mathrm{Ca}^{2+}$ stores, which are comprised of the endoplasmic reticulum and the nuclear envelope. The $\mathrm{Ca}^{2+}$ release leads to the activation of $\mathrm{Ca}^{2+}$ entry from the extracellular space, which is called capacitative, or store-operated $\mathrm{Ca}^{2+}$ entry. These movements of $\mathrm{Ca}^{2+}$ are essential for DNA synthesis during S-phase. Spontaneous $\mathrm{Ca}^{2+}$ oscillations also occur synchronously across the cells. This synchronization is mediated by voltage fluctuations in the membrane potential of the nuclear envelope due to $\mathrm{Ca}^{2+}$ release and the counter movement of $\mathrm{K}^{+}$ions; the voltage fluctuation induces alternating current (AC), which is transmitted via capacitative electrical coupling to the neighboring cells. The membrane potential across the plasma membrane is stabilized through gap junction coupling by lowering the input resistance. Thus, stored $\mathrm{Ca}^{2+}$ ions are a key player in the maintenance of the cellular activity of neuroepithelial cells.
\end{abstract}

\section{Introduction}

During the embryonic development of the central nervous system, cells in the neuroepithelium act as neural stem cells. The neuroepithelium forms the neural tube, from which the central nervous system including the spinal cord, retina, and brain is derived. The neuroepithelial cell has a polarized structure: the apical process faces the ventricle, and the furthest portion of the basal process makes contact with the basement membrane. This contact is necessary for the cell to undergo interkinetic nuclear movement along the apicobasal axis during the cell cycle [1-4]. Neuroepithelial cells in S-phase synthesize DNA in their basal region, followed by the movement of the soma towards the apical region prior to cell division during M-phase [3, 4].

To study ion channel activities in the neuroepithelial cell, the retinal neuroepithelium is a suitable model because the retina can be isolated from an optic cup at early stages of embryonic development. The neural tube evaginates laterally to form two optic vesicles, each of which invaginates to form an optic cup. The neuroepithelium on the inner wall of the optic cup becomes the retina. Figure 1 shows the retinal neuroepithelial cells that are undergoing interkinetic nuclear movements and the first differentiated neuron, a retinal ganglion cell. Developmental changes in the cellular activity are summarized as a time diagram in Figure 2. Studies of the retinal neuroepithelial cells have revealed that various ion channels are assembled in these cells and are important for the maintenance of the cellular activity of neuroepithelial cells. The current paper is intended to survey and discuss the functional roles of ion channels found in the retinal neuroepithelial cell, as well as in other neural tube stem cells, and the cell line.

\section{Channel-Mediated Release of $\mathrm{Ca}^{2+}$ from Intracellular $\mathrm{Ca}^{2+}$ Stores}

Neuroepithelial cells show a robust response to the activation of $\mathrm{G}$ protein-coupled receptors (GPCRs) including 


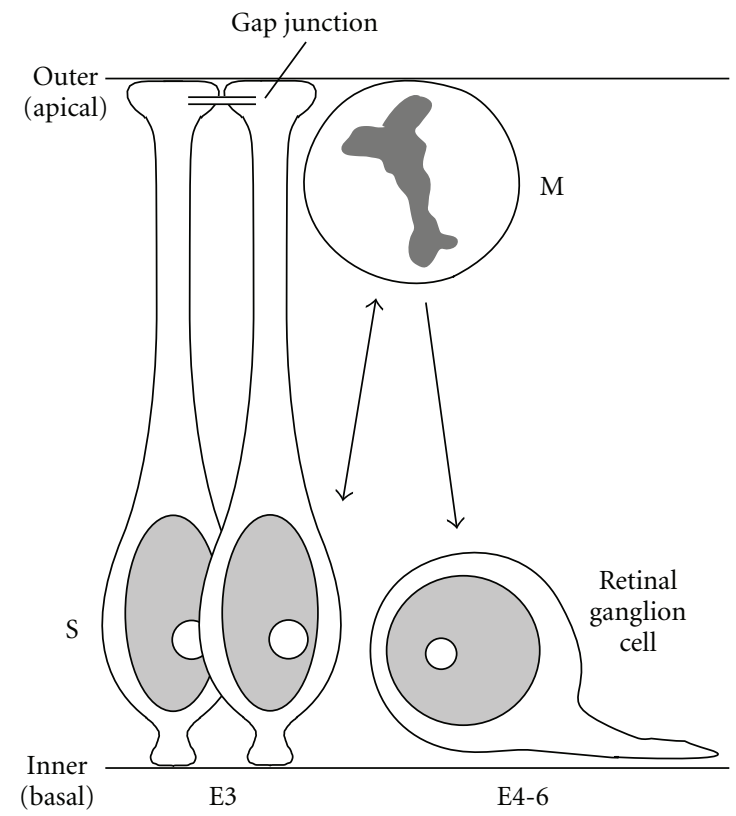

FIGURE 1: Schematic drawings of retinal neuroepithelial cells in cell cycle and the first differentiated neuron, a retinal ganglion cell. In chick embryo, the retina is composed almost homogeneously of neuroepithelial cells on embryonic day 3 (E3). The retinal ganglion cells are born mainly at E4-6. S: S-phase; M: M-phase. The outer (apical) surface faces the space that is continuous with the ventricle. This figure is cited from [5].

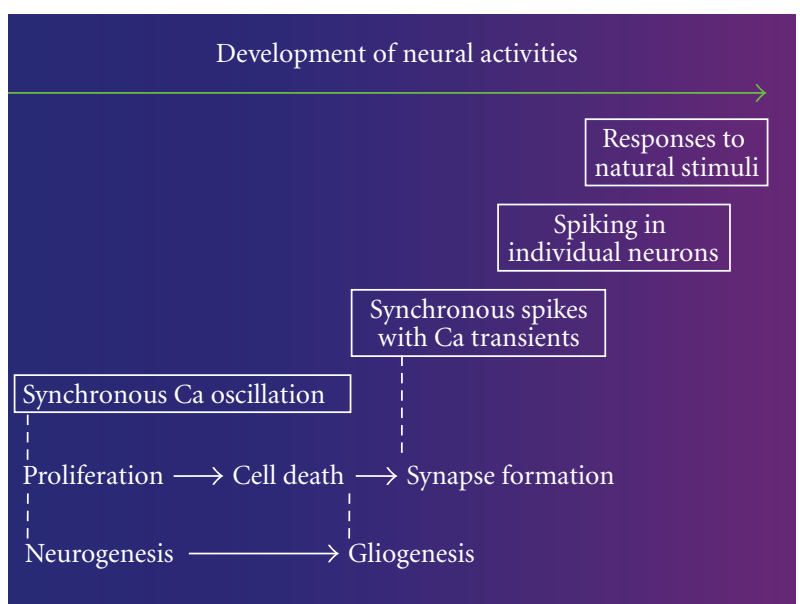

FIGURE 2: Developmental changes in neural activities. Self-renewing neuroepithelial cells show spontaneous, synchronous calcium oscillations. Newborn neurons show synchronous burst spike discharges before synapse formation. This figure is cited from [6].

muscarinic acetylcholine receptors [7], P2Y purinoceptors [8], and lysophosphatidic acid receptors [9], which leads to increases in intracellular $\mathrm{Ca}^{2+}$ concentrations $\left(\left[\mathrm{Ca}^{2+}\right]\right)$. Activation of these GPCRs leads to the production of inositol 1,4,5-trisphosphate $\left(\mathrm{InsP}_{3}\right)$ from phosphatidylinositol 4,5bisphosphate $\left(\mathrm{PIP}_{2}\right)$ via the phospholipase $\mathrm{C}$ enzyme. $\mathrm{InsP}_{3}$ activates the $\mathrm{InsP}_{3}$ receptor $\mathrm{Ca}^{2+}$ channel to cause the release of $\mathrm{Ca}^{2+}$ from intracellular $\mathrm{Ca}^{2+}$ stores $\left(\mathrm{Ca}^{2+}\right.$ mobilization) [10]. Another type of $\mathrm{Ca}^{2+}$ releasing channel, namely ryanodine receptor channel, is unlikely to be functioning in the retinal neuroepithelial cell because no response was evoked by caffeine (an activator of ryanodine receptor) [8].
Using confocal fluorescence microscopy and a $\mathrm{Ca}^{2+}$ sensitive fluorescent indicator, it was shown that $\mathrm{Ca}^{2+}$ mobilization is dependent upon the cell cycle [11]. Increases in intracellular $\left[\mathrm{Ca}^{2+}\right]$ occur in the nucleoplasm of S-phase cells, of which somata are localized to the basal region of the developing neuroepithelium. In contrast, $\mathrm{Ca}^{2+}$ mobilization decreases in M-phase cells, which are located in the apical region. In newborn retinal ganglion cells, which migrate to the basal region (Figure 1), $\mathrm{Ca}^{2+}$ mobilization is also reduced. These results suggest that the rise in nucleoplasmic $\left[\mathrm{Ca}^{2+}\right]$ is necessary for DNA synthesis during S-phase and that the $\mathrm{Ca}^{2+}$ mobilization system is less active following neuronal 
differentiation [11]. It is not clear whether other phases in cell cycle (i.e., $\mathrm{G}_{1}$ or $\mathrm{G}_{2}$ ) show $\mathrm{Ca}^{2+}$ increases.

The GPCR-mediated $\mathrm{Ca}^{2+}$ response of the neuroepithelial cell also depends upon the developmental stage of the retina. On embryonic day 3 (E3), nearly all the cells in the neural retina arise from the self-renewal of the neuroepithelial cells (Figure 1), and the $\mathrm{Ca}^{2+}$ mobilization is most robust at this stage. Retinal ganglion cells and other types of neurons are born between $\mathrm{E} 4$ and $\mathrm{E}$ 8, and then neurogenesis ceases [12]. Between E3 and E8, the $\mathrm{Ca}^{2+}$ response declines in parallel with the decreasing proliferative activity of the retinal cells $[7-9,13]$. This developmental profile suggests that $\mathrm{Ca}^{2+}$ mobilization may be critical for the proliferation of neuroepithelial cells. In support of this concept, studies using retinal cell cultures have shown that the release of $\mathrm{Ca}^{2+}$ from intracellular $\mathrm{Ca}^{2+}$ store is essential for DNA synthesis in these cells [14].

Increases in $\mathrm{Ca}^{2+}$ mobilization also occur spontaneously as synchronized $\mathrm{Ca}^{2+}$ oscillations in the retinal neuroepithelial cells [15] (Figure 2). GPCRs, such as P2Y purinoceptors, may be constitutively activated by ambient ATP, which is released in both an autocrine and paracrine manner [16]. The activation of P2Y purinoceptors has also been shown to promote the proliferation of retinal neuroepithelial cells [16-18]. The inhibitory effects of $\mathrm{P} 2$ antagonists on the proliferation of retinal neuroepithelial cells suggest that endogenous ATP activates P2Y purinoceptors constitutively [16]. The mechanism underlying the synchronization of $\mathrm{Ca}^{2+}$ oscillations is discussed later in this text.

Increases in the intracellular $\left[\mathrm{Ca}^{2+}\right]$ of S-phase cells may be involved in the activation of $\mathrm{Ca}^{2+}$-dependent nuclear signaling for proliferation. It has been suggested in various cell types that calcineurin, a $\mathrm{Ca}^{2+} /$ calmodulindependent phosphatase, dephosphorylates the transcription factor NFAT (nuclear factor of activated T-lymphocytes), which regulates cell cycle progression $[19,20]$.

\section{Store-Operated $\mathrm{Ca}^{2+}$ Entry}

The release of $\mathrm{Ca}^{2+}$ from intracellular $\mathrm{Ca}^{2+}$ stores has been shown to instantaneously induce an influx of extracellular $\mathrm{Ca}^{2+}$. This $\mathrm{Ca}^{2+}$ influx is called capacitative or store-operated $\mathrm{Ca}^{2+}$ entry, and is necessary for the replenishment of the intracellular $\mathrm{Ca}^{2+}$ stores $[21,22]$. This type of $\mathrm{Ca}^{2+}$ influx also occurs in the retinal neuroepithelial cell [23].

The store-operated $\mathrm{Ca}^{2+}$ entry in the retinal neuroepithelial cell has also been shown to decline as the cell becomes increasingly differentiated $[13,23]$. Store-operated $\mathrm{Ca}^{2+}$ entry has also been shown to be essential for DNA synthesis in cultured retinal cells [14]. In a culture model of neural stem cells, neuroblastoma $\times$ glioma NG108-15 cell line, store-operated $\mathrm{Ca}^{2+}$ entry is most frequent in proliferation, as opposed to neuronal differentiation, medium [24]. It has been suggested that the store-operated $\mathrm{Ca}^{2+}$ entry is also involved in the $\mathrm{Ca}^{2+}$-regulated transcription pathways for cell cycle progression via the activation of calcineurin and NFAT $[19,20]$.
The channels responsible for capacitative $\mathrm{Ca}^{2+}$ entry have been supposed to be transient receptor potential (TRP) channels $[21,22]$. It is now evident that the STIM molecules function as $\mathrm{Ca}^{2+}$ sensors within the endoplasmic reticulum and the orai proteins function as the channel for $\mathrm{Ca}^{2+}$ influx $[21,22]$. The specific channels involved in the store-operated $\mathrm{Ca}^{2+}$ entry in the neuroepithelial cell have not yet been identified.

\section{Ligand-Gated Channels}

Retinal neuroepithelial cells also express ligand-gated channels. Application of the neurotransmitter gamma-aminobutyric acid (GABA) causes a strong depolarization that leads to the activation of L-type $\mathrm{Ca}^{2+}$ channels, allowing $\mathrm{Ca}^{2+}$ influx [25]. The GABA-induced depolarization is due to the efflux of $\mathrm{Cl}^{-}$ions through $\mathrm{GABA}_{\mathrm{A}}$ receptor channels, since the intracellular $\left[\mathrm{Cl}^{-}\right]$in the retinal neuroepithelial cell is higher than that in a mature neuron and the equilibrium potential of $\mathrm{Cl}^{-}$is more positive than the resting membrane potential [25].

The GABA-induced depolarization and $\mathrm{Ca}^{2+}$ influx through voltage-dependent $\mathrm{Ca}^{2+}$ channels have been shown to inhibit the DNA synthesis in cortical progenitor cells [26] and the cell cycle progression in neuronal precursors from striatum [27]. On the contrary, by causing influx of $\mathrm{Cl}^{-}$ions and hyperpolarization, GABA has been shown to negatively control the proliferation in embryonic stem (ES) cells and neural crest stem (NCS) cells [28].

In addition to GABA, ATP depolarizes retinal neuroepithelial cells by activating P2X purinoceptor channels as revealed by intracellular recording from these cells (unpublished observation).

\section{Gap Junctions as Stabilizers of Membrane Potential}

Neuroepithelial cells adhere to each other through gap junctions, which are located at the apical process of the cell [29]. This gap junction coupling between retinal neuroepithelial cells was demonstrated by the intracellular injection of a fluorescent dye and the subsequent dye diffusion (dye coupling) [5]. Following application of the gap junction channel blocker carbenoxolone during intracellular recording from retinal neuroepithelial cells, it was demonstrated that the input resistance was dramatically increased. In addition, the membrane potential was depolarized and rendered unstable showing fluctuations during the recording in the presence of the blocker [5]. These results suggest that the gap junction coupling stabilizes the resting membrane potential of the neuroepithelial cell by lowering the input resistance. This characteristic of gap junction coupling in the neuroepithelial cell may underlie the maintenance of the driving force for $\mathrm{Ca}^{2+}$ influx during store-operated $\mathrm{Ca}^{2+}$ entry and the prevention of the excess, continuous influx of $\mathrm{Ca}^{2+}$ through L-type $\mathrm{Ca}^{2+}$ channels. 


\section{6. $\mathrm{Na}^{+}, \mathrm{Ca}^{2+}$, and $\mathrm{K}^{+}$Channels in the Plasma Membrane}

The neuroepithelial cell shows epithelial features including not only the polarized structure but also physiological properties. Studies of the chick retinal neuroepithelium and the amphibian neural tube have shown that neuroepithelial cells are nonexcitable $[5,30]$. Instead of voltage-dependent $\mathrm{Na}^{+}$ channels, amiloride-sensitive epithelial-type $\mathrm{Na}^{+}$channels are present in cells of the neural tube [31]. These channels allow a continuous influx of $\mathrm{Na}^{+}$from the ventricular space, and $\mathrm{Na}^{+}-\mathrm{K}^{+}$pumps extrude $\mathrm{Na}^{+}$ions from the cell to generate the transneural tube potential (a lumen-negative DC potential) in the amphibian embryo [31]. An extracellular DC potential was also observed within the retinal neuroepithelium (unpublished observation). The polarized transport of $\mathrm{Na}^{+}$from the ventricular space may contribute to the establishment of the DC potential. The retinal neuroepithelium is an electrically tight epithelium since the extracellular resistance is extremely high $(\geq 300 \mathrm{M} \Omega)$ in the middle region of the retinal neuroepithelium (unpublished observation).

Voltage-gated $\mathrm{Ca}^{2+}$ channels are also present in the retinal neuroepithelial cell. $\mathrm{Ca}^{2+}$-sensitive fluorescence measurements revealed the presence of L-type channels [25]. The Ltype $\mathrm{Ca}^{2+}$ channel allows a continuous $\mathrm{Ca}^{2+}$ influx when the cell is depolarized with a high concentration of extracellular $\mathrm{K}^{+}$[25]. Since retinal neuroepithelial cells are interconnected through gap junctions, lowering the input resistance [5], it seems likely that these channels are activated only when a mass of cells are depolarized. A single neuroepithelial cell does not generate any spike-like potential, even following the injections of a strong depolarizing current [5]. Thus, the role of the L-type $\mathrm{Ca}^{2+}$ channel in these cells remains to be clarified. It can be supposed that if L-type $\mathrm{Ca}^{2+}$ channels are activated by GABA-induced depolarization after losing gap junction, the $\mathrm{Ca}^{2+}$ influx through these channels may inhibit cell cycle progression, as revealed in neural progenitor cells $[26,27]$. It has also been shown that the influx of $\mathrm{Ca}^{2+}$ through L-type $\mathrm{Ca}^{2+}$ channels prevents apoptosis in culture models of neuronal death [32].

BK (big potassium, $\mathrm{Ca}^{2+}$ - and voltage-dependent potassium) channels in the plasma membrane are activated by increases in intracellular $\left[\mathrm{Ca}^{2+}\right]$, which may be caused by $\mathrm{Ca}^{2+}$ influx through voltage-dependent $\mathrm{Ca}^{2+}$ channels during depolarization. Cells expressing BK channels in the plasma membrane show a voltage sag in response to a depolarizing current injection. This is the case in newborn retinal ganglion cells, which do not yet generate a tetrodotoxinsensitive $\mathrm{Na}^{+}$-dependent action potential [5]. The newborn ganglion cell loses its gap junction coupling, thus the input resistance is increased and the voltage response in the cell is rendered visible [5]. The voltage sag in response to a depolarizing current injection is also observed in retinal neuroepithelial cells in which the gap junction channels are blocked by carbenoxolone [5]. These data suggest that BK channels are also present in the plasma membrane of retinal neuroepithelial cells. It seems likely that the BK channels in the plasma membrane repolarize the membrane potential when intracellular $\left[\mathrm{Ca}^{2+}\right]$ is increased.

\section{BK Channels in the Nuclear Envelope and Endoplasmic Reticulum}

Intracellular $\mathrm{Ca}^{2+}$ stores are comprised of the endoplasmic reticulum and the nuclear envelope $[33,34]$. The lumen of the endoplasmic reticulum is continuous with the space between the outer and inner nuclear membranes [35]. $\mathrm{Ca}^{2+}$ ions are actively transported into this lumen by $\mathrm{Ca}^{2+}$ pumps.

The release of $\mathrm{Ca}^{2+}$ from intracellular stores via $\mathrm{InsP}_{3}$ receptor channels leads to a charge movement across the store membrane from the lumen to the cytoplasm or to the nucleoplasm, which are electrically interconnected through low-resistance nuclear pores [36]. This charge movement should lead to a negative shift in the luminal potential [37]. Simultaneous measurements of the nuclear membrane potential and intracellular $\left[\mathrm{Ca}^{2+}\right]$ revealed that the potential of the nuclear membrane changes in a biphasic manner together with the activation of GPCRs, leading to a transient hyperpolarization and a sustained depolarization associated with the release of $\mathrm{Ca}^{2+}$ and the electrogenic pumping of $\mathrm{Ca}^{2+}$ ions, respectively [38].

To maintain the driving force for $\mathrm{Ca}^{2+}$ release from intracellular stores, the counter movement of ions, such as $\mathrm{K}^{+}$, across the store membrane is absolutely necessary; without counter ion movement, the luminal potential hyperpolarizes to the equilibrium potential of $\mathrm{Ca}^{2+}$ and the driving force for $\mathrm{Ca}^{2+}$ release is lost [37]. In the sarcoplasmic reticulum, TRIC (trimeric intracellular cation) channels mediate the counter ion movement [39].

Patch clamp recordings from the nuclear envelope membrane have shown that this membrane contains BK channels and that these BK channels are activated by positive changes in the luminal potential (depolarization) and by an increase in the luminal $\left[\mathrm{Ca}^{2+}\right][15,40]$. Such voltage and $\mathrm{Ca}^{2+}$ dependence may suggest that hyperpolarization caused by the release of $\mathrm{Ca}^{2+}$ and a decrease in the luminal $\left[\mathrm{Ca}^{2+}\right]$, together lead to the closure of the BK channel and cessation of $\mathrm{Ca}^{2+}$ release from the lumen. This has been proposed to be a hypothetical underlying mechanism to explain the "quantal" manner of $\mathrm{Ca}^{2+}$ release, in which $\mathrm{Ca}^{2+}$ release terminates after a rapid release of a fraction of stored $\mathrm{Ca}^{2+}$ [41].

\section{Nuclear Envelope Potential and the Synchronization of Cellular Activity}

Spontaneous $\mathrm{Ca}^{2+}$ oscillations occur synchronously across the cells in the retinal neuroepithelium, while agonistinduced $\left[\mathrm{Ca}^{2+}\right]$ rises occur asynchronously [15]. The mechanism underlying the synchronization of $\mathrm{Ca}^{2+}$ oscillations has been a matter of debate [42]. The diffusion of $\operatorname{InsP}_{3}$ or $\mathrm{Ca}^{2+}$ itself through gap junction channels is unlikely to synchronize a $\left[\mathrm{Ca}^{2+}\right]$ rise, because an agonist-induced $\mathrm{Ca}^{2+}$ release is not synchronized even with the application of a supramaximal concentration of the agonist [15, 42]. Instead, a capacitative, or AC (alternating current), electrical coupling model has been proposed [6]. In this model, the efflux of $\mathrm{Ca}^{2+}$ from intracellular stores and the counter 
TABLE 1: Neuroepithelial-cell-ion channels and their functions.

\begin{tabular}{ll}
\hline Type of ion channel & Function of ion channel \\
\hline & Ion channels in the plasma membrane \\
Gap junction channel & Stabilizing membrane potential by lowering input resistance \\
Store-operated $\mathrm{Ca}^{2+}$ entry channel (TRP or Orai) & Replenishing $\mathrm{Ca}^{2+}$ stores after $\mathrm{Ca}^{2+}$ release \\
Epithelial Na ${ }^{+}$channel & Continuous $\mathrm{Na}^{+}$influx from ventricular space to generate DC potential \\
L-type voltage-dependent $\mathrm{Ca}^{2+}$ channel & $\mathrm{Ca}^{2+}$ influx by depolarization \\
$\mathrm{BK}$ channel & Repolarizating after depolarization and intracellular $\left[\mathrm{Ca}^{2+}\right]$ rise \\
$\mathrm{GABA}_{\mathrm{A}}$ receptor channel & Depolarizing in response to GABA \\
$\mathrm{P} 2 \mathrm{X}$ purinoceptor channel & Depolarizing in response to ATP \\
\hline
\end{tabular}

Ion channels in the nuclear envelope and the endoplasmic reticulum

$\mathrm{Ins}_{3}$ receptor channel

$\mathrm{Ca}^{2+}$ release by activation of muscarinic acetylcholine receptor, P2Y purinoceptor, and lysophosphatidic acid receptor

BK channel

Counter ion movement for $\mathrm{Ca}^{2+}$ release to maintain driving force for $\mathrm{Ca}^{2+}$ release

influx of $\mathrm{K}^{+}$into the store lumen cause alternating voltage changes across the store membrane, and this voltage fluctuation induces AC currents. In the neuroepithelial cell, the outer nuclear membrane is closely apposed to the plasma membrane, and the cells are tightly packed $[6,15,38]$. Thus, it is plausible that the voltage fluctuation in the nuclear envelope potential is synchronized across the cells by the AC current being transferred in series via the capacitance of the outer nuclear membrane and the plasma membrane $[6,41]$. Real-time confocal fluorescence measurements using an organelle-specific voltage-sensitive dye revealed that the nuclear membrane potential generates spontaneous repeats of high frequency $(100-300 \mathrm{~Hz})$ bursts of fluctuations in potential [38]. Furthermore, oscillatory changes in nuclear membrane potential underlie spike burst generation in developing neurons prior to synapse formation [38]. These results support the capacitative coupling model, in which voltage fluctuations in the nuclear membrane potential synchronize $\mathrm{Ca}^{2+}$ release across the population of cells and also function as a current noise generator to cause synchronous burst spike discharges in the neurons at an early stage of neural development $[6,38]$.

\section{Concluding Remarks}

Table 1 summarizes the different types and functions of ion channels expressed by neuroepithelial cells. While neurons use voltage changes across the plasma membrane, such as action potentials and synaptic potentials, for intercellular communication, the neuroepithelial cell uses stored $\mathrm{Ca}^{2+}$ ions to enable proliferation as well as the synchronization of $\mathrm{Ca}^{2+}$ oscillations. This synchronization is mediated by voltage fluctuations in the membrane potential of the nuclear envelope that allow capacitative (AC) electrical coupling between the cells. The membrane potential across the plasma membrane is stabilized via gap junction coupling, which lowers the input resistance of the neuroepithelial cell. BK-type potassium channels may also contribute to the stabilization of the plasma membrane potential when intracellular $\left[\mathrm{Ca}^{2+}\right]$ is increased. Thus, stored $\mathrm{Ca}^{2+}$ ions are a key player in the maintenance of the cellular activity of neuroepithelial cells.

\section{References}

[1] F. C. Sauer, "Mitosis in the neural tube," The Journal of Comparative Neurology, vol. 62, no. 2, pp. 377-405, 1935.

[2] S. Fujita, "Mitotic pattern and histogenesis of the central nervous system," Nature, vol. 185, no. 4714, pp. 702-703, 1960.

[3] S. Fujita, "The matrix cell and cytogenesis in the developing central nervous system," Journal of Comparative Neurology, vol. 120, no. 1, pp. 37-42, 1963.

[4] Y. Kosodo, T. Suetsugu, M. Suda et al., "Regulation of interkinetic nuclear migration by cell cycle-coupled active and passive mechanisms in the developing brain," The EMBO Journal, vol. 30, no. 9, pp. 1690-1704, 2011.

[5] M. Yamashita, "Synchronous $\mathrm{Ca}^{2+}$ oscillation emerges from voltage fluctuations of $\mathrm{Ca}^{2+}$ stores," The FEBS Journal, vol. 275, no. 16, pp. 4022-4032, 2008.

[6] M. Yamashita, "Synchronization of $\mathrm{Ca}^{2+}$ oscillations: a capacitative (AC) electrical coupling model in neuroepithelium," The FEBS Journal, vol. 277, no. 2, pp. 293-299, 2010.

[7] M. Yamashita, Y. Yoshimoto, and Y. Fukuda, "Muscarinic acetylcholine responses in the early embryonic chick retina," Journal of Neurobiology, vol. 25, no. 9, pp. 1144-1153, 1994.

[8] M. Sugioka, Y. Fukuda, and M. Yamashita, " $\mathrm{Ca}^{2+}$ responses to ATP via purinoceptors in the early embryonic chick retina," Journal of Physiology, vol. 493, no. 3, pp. 855-863, 1996.

[9] W. L. Zhou, M. Sugioka, and M. Yamashita, "Lysophosphatidic acid-induced $\mathrm{Ca}^{2+}$ mobilization in the neural retina of chick embryo," Journal of Neurobiology, vol. 41, no. 4, pp. 495-504, 1999.

[10] Y. Sakaki, Y. Fukuda, and M. Yamashita, "Muscarinic and purinergic $\mathrm{Ca}^{2+}$ mobilizations in the neural retina of early embryonic chick," International Journal of Developmental Neuroscience, vol. 14, no. 6, pp. 691-699, 1996.

[11] M. Sugioka and M. Yamashita, "Calcium signaling to nucleus via store-operated system during cell cycle in retinal neuroepithelium," Neuroscience Research, vol. 45, no. 4, pp. 447-458, 2003.

[12] C. Prada, J. Puga, L. Pérez-Méndez, R. López, and G. Ramírez, "Spatial andtemporal patterns of neurogenesis in the chick 
retina," European Journal of Neuroscience, vol. 3, no. 6, pp. 559569, 1991.

[13] M. Yamashita and M. Sugioka, "Calcium mobilization systems during neurogenesis," News in Physiological Sciences, vol. 13, no. 2, pp. 75-79, 1998.

[14] M. Sugioka, W. L. Zhou, H. D. Hofmann, and M. Yamashita, " $\mathrm{Ca}^{2+}$ mobilization and capacitative $\mathrm{Ca}^{2+}$ entry regulate DNA synthesis in cultured chick retinal neuroepithelial cells," International Journal of Developmental Neuroscience, vol. 17, no. 3, pp. 163-172, 1999.

[15] M. Yamashita, M. Sugioka, and Y. Ogawa, "Voltage- and $\mathrm{Ca}^{2+}$-activated potassium channels in $\mathrm{Ca}^{2+}$ store control $\mathrm{Ca}^{2+}$ release," The FEBS Journal, vol. 273, no. 15, pp. 3585-3597, 2006.

[16] M. Sugioka, W. L. Zhou, H. D. Hofmann, and M. Yamashita, "Involvement of P2 purinoceptors in the regulation of DNA synthesis in the neural retina of chick embryo," International Journal of Developmental Neuroscience, vol. 17, no. 2, pp. 135144, 1999.

[17] G. Sanches, L. S. Alencar, and A. L. M. Ventura, "ATP induces proliferation of retinal cells in culture via activation of PKC and extracellular signal-regulated kinase cascade," International Journal of Developmental Neuroscience, vol. 20, pp. 21-27, 2002.

[18] I. M. Ornelas and A. L. M. Ventura, "Involvement of the PI3K/AKT pathway in ATP-induced proliferation of developing retinal cells in culture," International Journal of Developmental Neuroscience, vol. 28, no. 6, pp. 503-511, 2010.

[19] L. Lipskaia and A. M. Lompré, "Alteration in temporal kinetics of $\mathrm{Ca}^{2+}$ signaling and control of growth and proliferation," Biology of the Cell, vol. 96, no. 1, pp. 55-68, 2004.

[20] L. Lipskaia, J. S. Hulot, and A. M. Lompré, "Role of sarco/endoplasmic reticulum calcium content and calcium ATPase activity in the control of cell growth and proliferation," Pflügers Archiv-European Journal of Physiology, vol. 457, no. 3, pp. 673-685, 2009.

[21] M. Potier and M. Trebak, "New developments in the signaling mechanisms of the store-operated calcium entry pathway," Pflügers Archiv-European Journal of Physiology, vol. 457, no. 2, pp. 405-415, 2008.

[22] J. T. Smyth, S. Y. Hwang, T. Tomita, W. I. DeHaven, J. C. Mercer, and J. W. Putney, "Activation and regulation of storeoperated calcium entry," Journal of Cellular and Molecular Medicine, vol. 14, no. 10, pp. 2337-2349, 2010.

[23] Y. Sakaki, M. Sugioka, Y. Fukuda, and M. Yamashita, "Capacitative $\mathrm{Ca}^{2+}$ influx in the neural retina of chick embryo," Journal of Neurobiology, vol. 32, no. 1, pp. 62-68, 1997.

[24] J. Ichikawa, Y. Fukuda, and M. Yamashita, "In vitro changes in capacitative $\mathrm{Ca}^{2+}$ entry in neuroblastoma X glioma NG108-15 cells," Neuroscience Letters, vol. 246, no. 2, pp. 120-122, 1998.

[25] M. Yamashita and Y. Fukuda, "Calcium channels and GABA receptors in the early embryonic chick retina," Journal of Neurobiology, vol. 24, no. 12, pp. 1600-1614, 1993.

[26] J. J. LoTurco, D. F. Owens, M. J. S. Heath, M. B. E. Davis, and A. R. Kriegstein, "GABA and glutamate depolarize cortical progenitor cells and inhibit DNA synthesis," Neuron, vol. 15, no. 6, pp. 1287-1298, 1995.

[27] L. Nguyen, B. Malgrange, I. Breuskin et al., "Autocrine/paracrine activation of the $\mathrm{GABA}_{\mathrm{A}}$ receptor inhibits the proliferation of neurogenic polysialylated neural cell adhesion molecule-positive (PSA-NCAM ${ }^{+}$) precursor cells from postnatal striatum," Journal of Neuroscience, vol. 23, no. 8, pp. 3278-3294, 2003.
[28] M. Andäng, J. Hjerling-Leffler, A. Moliner et al., "Histone $\mathrm{H} 2 \mathrm{AX}$-dependent $\mathrm{GABA}_{\mathrm{A}}$ receptor regulation of stem cell proliferation," Nature, vol. 451, no. 7177, pp. 460-464, 2008.

[29] H. Fujisawa, H. Morioka, K. Watanabe, and H. Nakamura, "A decay of gap junctions in association with cell differentiation of neural retina in chick embryonic development," Journal of Cell Science, vol. 22, no. 3, pp. 585-596, 1976.

[30] A. E. Warner, "The electrical properties of the ectoderm in the amphibian embryo during induction and early development of the nervous system," Journal of Physiology, vol. 235, no. 1, pp. 267-286, 1973.

[31] R. Shi and R. B. Borgens, "Embryonic neuroepithelial sodium transport, the resulting physiological potential, and cranial development," Developmental Biology, vol. 165, no. 1, pp. 105116, 1994.

[32] J. L. Franklin and E. M. Johnson Jr., "Block of neuronal apoptosis by a sustained increase of steady-state free $\mathrm{Ca}^{2+}$ concentration," Philosophical Transactions of the Royal Society of London. Series B, vol. 345, no. 1313, pp. 251-256, 1994.

[33] O. V. Gerasimenko, J. V. Gerasimenko, A. V. Tepikin, and O. H. Petersen, "Calcium transport pathways in the nucleus," Pflügers Archiv-European Journal of Physiology, vol. 432, no. 1, pp. 1-6, 1996.

[34] O. H. Petersen, O. V. Gerasimenko, J. V. Gerasimenko, H. Mogami, and A. V. Tepikin, "The calcium store in the nuclear envelope," Cell Calcium, vol. 23, no. 2-3, pp. 87-90, 1998.

[35] G. K. Voeltz, M. M. Rolls, and T. A. Rapoport, "Structural organization of the endoplasmic reticulum," EMBO Reports, vol. 3, no. 10, pp. 944-950, 2002.

[36] M. Mazzanti, J. O. Bustamante, and H. Oberleithner, "Electrical dimension of the nuclear envelope," Physiological Reviews, vol. 81, no. 1, pp. 1-19, 2001.

[37] D. Burdakov, O. H. Petersen, and A. Verkhratsky, "Intraluminal calcium as a primary regulator of endoplasmic reticulum function," Cell Calcium, vol. 38, no. 3-4, pp. 303-310, 2005.

[38] M. Yamashita, "Fluctuations in nuclear envelope's potential mediate synchronization of early neural activity," Biochemical and Biophysical Research Communications, vol. 406, no. 1, pp. 107-111, 2011.

[39] M. Yazawa, C. Ferrante, J. Feng et al., "TRIC channels are essential for $\mathrm{Ca}^{2+}$ handling in intracellular stores," Nature, vol. 448, no. 7149, pp. 78-82, 2007.

[40] Y. Maruyama, H. Shimada, and J. Taniguchi, " $\mathrm{Ca}^{2+}$-activated $\mathrm{K}^{+}$-channels in the nuclear envelope isolated from single pancreatic acinar cells," Pflügers Archiv-European Journal of Physiology, vol. 430, no. 1, pp. 148-150, 1995.

[41] M. Yamashita, "'Quantal' $\mathrm{Ca}^{2+}$ release reassessed-a clue to oscillation and synchronization," FEBS Letters, vol. 580, no. 21, pp. 4979-4983, 2006.

[42] M. Yamashita, "Synchronization of $\mathrm{Ca}^{2+}$ oscillations: Is gap junctional coupling sufficient?" The FEBS Journal, vol. 277, no. 2, p. $277,2010$. 

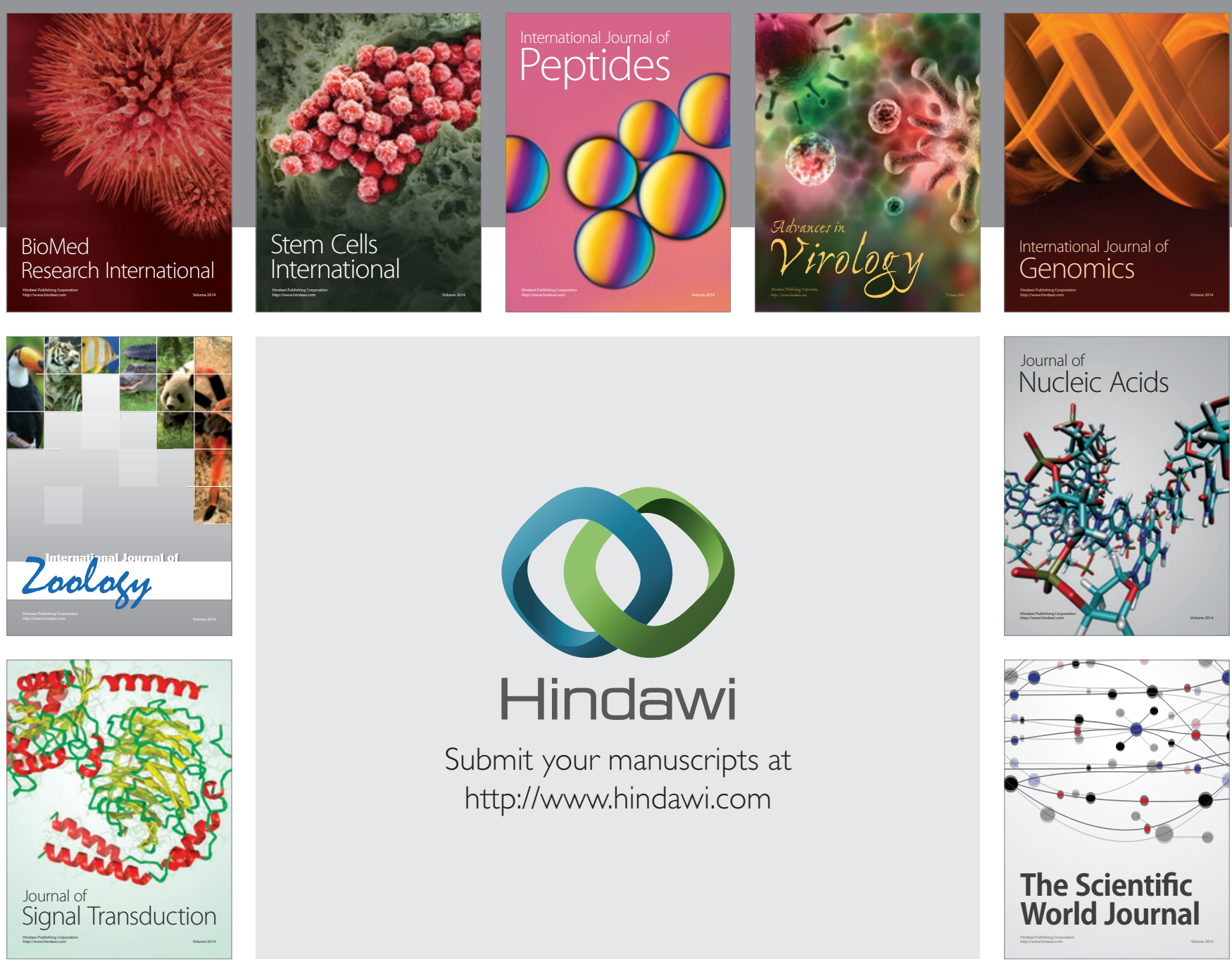

Submit your manuscripts at

http://www.hindawi.com
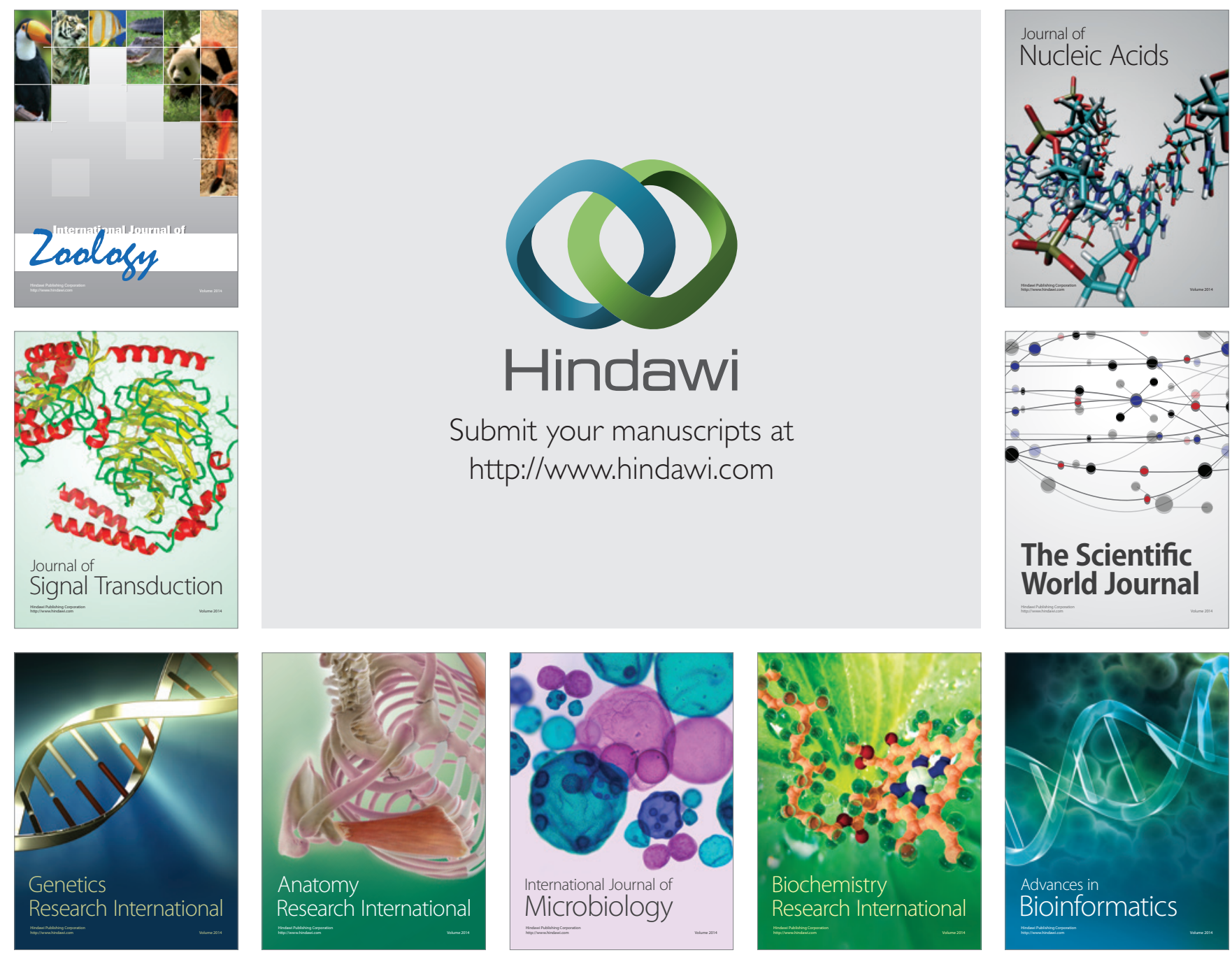

The Scientific World Journal
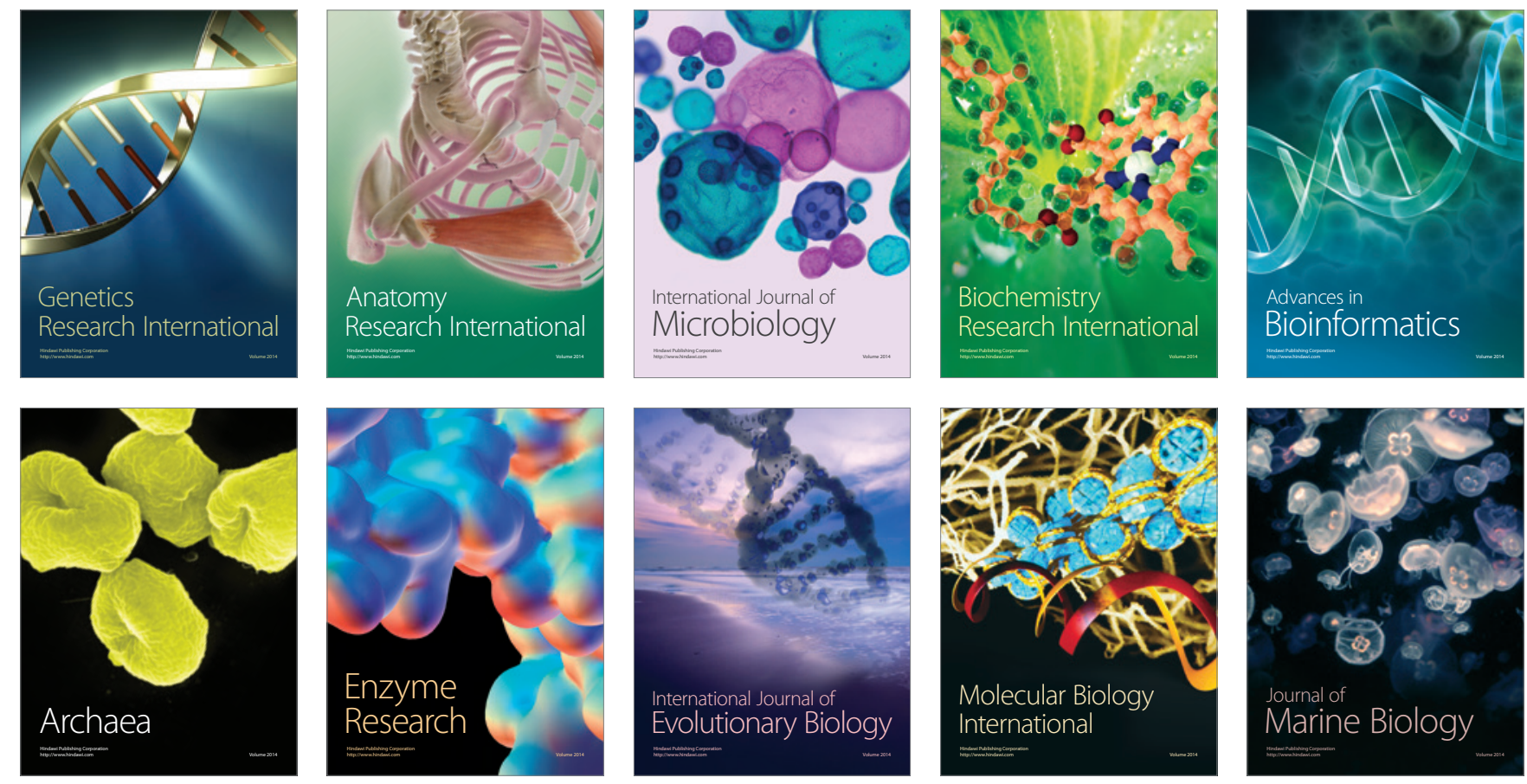